\title{
Identification of Trypanosoma Strains Isolated in Central and South America by Endoncleases Cleavage and Duplex PCR of Kinetoplast-DNA
}

\author{
Isabel Rodríguez-González ${ }^{\mathrm{a}}$, Clotilde Marín ${ }^{\mathrm{a}}$, Gregorio Pérez-Cordón ${ }^{\mathrm{a}}$, Ramón Gutiérrez-Sánchez \\ and Manuel Sánchez-Moreno*,a
}

\author{
${ }^{a}$ Instituto de Biotecnología, Departamento de Parasitología, Facultad de Ciencias, Universidad de Granada, C/ Severo \\ Ochoa s/n. 18071 Granada, Spain \\ ${ }^{b}$ Departamento de Estadística e I.O, Facultad de Ciencias, Universidad de Granada, C/ Severo Ochoa s/n. 18071 \\ Granada, Spain
}

\begin{abstract}
In this study, we report the characterization of seven trypanosome stocks isolated in different geographical areas of Latin America and from different vector species, by analysis of kinetoplast DNA (kDNA) restriction fragmentlength polymorphism, using five different restriction endonucleases, and genomic DNA by duplex PCR assay. According to the statistical study, the stocks were grouped into three clusters: cluster 1 held the three stocks of T. cruzi used as references. Very close to these were the stocks isolated in the Peruvian Amazon (TP702, TP704 and TP706), which constituted cluster 2. This cluster also included stock TP504, although this would be a hybrid between T. cruzi and T. rangeli. Cluster 3 consisted of the trypanosomes isolated from salivary glands (TRa, TRa605, TRa606 and TM5), these four stocks being the same as T. rangeli, and the phylogenetic separation observed could be due to having been isolated T. cruzi.
\end{abstract}

\section{INTRODUCTION}

Trypanosoma cruzi is the causal agent of Chagas disease, which is characterized by an acute phase after the initial infection and then a chronic phase in which there is a progressive degenerative disorder of the cardiac and/or gastrointestinal systems. Different isolates or $T$. cruzi stocks exhibit a great deal of heterogeneity in terms of isoenzyme patterns, surface antigens, nuclear-DNA content, morphological features, and kinetoplast minicircle DNA sequences [1].

During recent years, various research groups have demonstrated this broad biochemical, genetic, and molecular variability in populations of $T$. cruzi and $T$. rangeli, a species apparently not pathogenic for humans but very frequent in mixed infections by T. cruzi in some countries [2]. This heterogeneity and variability in its biological behaviour have hampered the establishment of suitable parameters for classification and taxonomy, making its characterization crucial in the Chagas disease clinic $[3,4]$.

In a previous paper, we characterized seven trypanosomatids isolated from different geographical areas of South America [5], using standard methods for taxonomic purposes [6,7]: isoenzyme analysis and lectins with different specificities for surface-membrane carbohydrate residues. More recently, it has been reported that the use of kinetoplast minicircle DNA sequences, by means of analysing the restriction enzymes or by polymerase chain-reaction on genomic DNA for this type of study are more precise, reliable, and appropriate [8]. For this, in this new study we have examined these seven isolates from Peru and Mexico by means of kDNA restriction fragment analysis and genomic DNA amplification by Duplex PCR assay. For comparison, we

*Address correspondence to this author at the Instituto de Biotecnología, Departamento de Parasitología, Facultad de Ciencias, Universidad de Granada, C/ Severo Ochoa s/n. 18071 Granada, Spain; Tel: +34 958 242369; Fax: +34 958 243174; E-mail: msanchem@ugr.es have used four isolates characterized as: $T$. cruzi stock Maracay, stock Y, stock CL, and T. rangeli.

\section{MATERIALS AND METHODOLOGY}

\section{Parasites}

The seven stocks isolated from different areas of South America: TM5 from Triatoma dimidiata in the Yucatan Peninsula of Mexico; the TP504 isolate of Panstrongylus chinai in the department of La Libertad in northern Peru; the TP702 and TP706, isolates of Triatoma carrioni and T. herreri, respectively, in the department of Amazonas in north-eastern Peru; the TP704 isolate of $T$. infestans in the department of Arequipa in south-eastern Peru; and the TRa605 and TRa606 isolates, both from the salivary glands of two Rhodnius ecuadoriensis in the department of La Libertad, Peru. For comparison, we also included T. cruzi (TC) Maracay, originally isolated from a clinical case in the Malariological Division of Environmental Health of Maracay (Venezuela) strain; T. cruzi (TY) strain Y [9]; T. cruzi (TCL) strain CL [10], and T. rangeli (TRa, Cajamarca-Peru strain), isolated from the salivary glands of Rhodnius ecuadoriensis [7] and maintained in our laboratory by routine procedures [11].

After isolation, the new flagellates were transferred to the biphasic culture medium Nicolle Nocloe Novi and MacNeal medium, supplemented with minimal essential medium, and $20 \%$ inactivated foetal bovine serum. The isolates were cloned and cultured in vitro using Grace's medium (Sigma) [11]. The parasites were inoculated at a density of $1.6 \times 10^{6}$ into $5 \mathrm{~mL}$ of medium in $25-\mathrm{mL}$ flacon flasks, and cultured at $28^{\circ} \mathrm{C}$. Aliquots were taken every $24 \mathrm{~h}$ for 9 days and the number of parasites was counted in a Neubauer haemocytometer. On the last day, the cells were removed by centrifugation at $600 \mathrm{~g}$ for $10 \mathrm{~min}$.

\section{Genomic-DNA Extraction}

For the extraction of genomic DNA, $10^{8}$ to $10^{9}$ cells were pelleted by centrifugation, washed in cold phosphate-buf- 
fered saline $(\mathrm{pH} 7.2)$, and resuspended in lysis buffer (10 $\mathrm{mM}$ Tris [pH 8.0], $100 \mathrm{mM}$ EDTA, $20 \mu \mathrm{g} / \mathrm{ml}$ Pancreatic Rnase, $0.5 \%$ sodium dodecyl sulphate). Proteinase $\mathrm{K}$ (Promega) was added to a final concentration of $100 \mathrm{mg} / \mathrm{ml}$, and the suspension was incubated overnight at $37^{\circ} \mathrm{C}$. After sequential extraction with phenol, phenol-chloroform, and chloroform, the DNA was precipitated by the addition $0.3 \mathrm{M}$ sodium acetate and 2,5 volumes of ethanol. The pellet was washed with $70 \%$ ethanol, air dried, resuspended in TE (10 $\mathrm{mM}$ Tris $\mathrm{HCl}$ [pH 7.2], 1 mM EDTA).

\section{Kinetoplast-DNA Isolation}

Epimastigote forms were collected by centrifugation of $300 \mathrm{~mL}$ of culture medium when their concentrations had reached about $2 \times 10^{7}$ cells $/ \mathrm{mL}$. They were washed twice in $50 \mathrm{~mL}$ of $0.15 \mathrm{M} \mathrm{NaCl}, 0.015 \mathrm{M}$ sodium citrate and once with SE buffer (0.15 M NaCl, 0.1 M EDTA, pH 8.0). Kinetoplast DNA was obtained according to the procedure described by [12].

\section{Restriction-Enzyme Digestion and Electrophoresis Analysis}

The kDNA extracts $(3 \mu \mathrm{g} / \mathrm{mL})$ were completely digested with restriction endonucleases (Hae III, BamH I, Hinf I, Msp I, and EcoR I) according to the manufacturer's prescribed buffer conditions (Boehringer-Ingelheim, Barcelona, Spain). The digestion products were electrophoresed in $1.3 \%$ agarose slab gels as described by [13], and the fragment sizes were estimated by comparing their mobilities with those of a $1 \mathrm{~kb}$ DNA ladder (Gibco-BRL, Gaithersburg, USA). The gels were stained with ethidium bromide $(10 \mu \mathrm{g} / \mathrm{mL}$ for 10 min) and photographed under UV light with a Polaroid camera (665 film).

\section{Analysis of Amplified Genomic DNA}

For polymerase chain reaction (PCR) assay, we used a MyCycler $^{\text {TM }}$ thermal cycler (Bio-Rad). The genomic DNA was obtained as described above. For $T$. cruzi detection, we used a modified version of a duplex PCR assay targeted to the 189-bp telomeric junction (Tc189, Gen Bank accession number AF100651). The primers were T189Fw2 (5'CCAACGCTCCGGGAAAAC-3') and Tc189Rv3 (5'GCGTCTTCTCAGTATGG ACTT-3'). For T. rangeli detection, we used an assay targeted to a conserved subtelomeric region (SubTr, GenBank accession number AF426020). The primers were TrF3 (5'-CCCCATACAAAACACCCTT-3') and TrR8 (5'-TGGAATGACGGTGCG GCGAC-3') [14]. All oligonucleotides were purchased from Thermo Electron Corporation (Germany) and PCR amplifications were conducted in a final volume of $25 \mu \mathrm{l}$ containing $0.2 \mathrm{mM}$ deoxynucleoside triphosphate mixture, $1.5 \mathrm{mM} \mathrm{MgCl}_{2}, 50 \mathrm{mM}$ KCI, 10 mM Tris-HCl (pH 9.0), 0.1\% Triton X-100, 0.24 $\mathrm{mM}$ deoxynucleoside triphosphate mix, $0.01 \%$ bovine serum albumin, $0.4 \mathrm{mM}$ each Tc189Fw2 and Tc189Rv3 primers, $0.67 \mathrm{mM}$ each TrF3 and TrR8 primers, $1.25 \mathrm{U}$ of Taq DNA polymerase (Promega), and $10 \mathrm{ng}$ of DNA preparation. An initial denaturing step at $94^{\circ} \mathrm{C}$ for 4 min was followed by 35 cycles of $30 \mathrm{~s}$ at $55^{\circ} \mathrm{C}, 40 \mathrm{~s}$ at $72^{\circ} \mathrm{C}$, and $1 \mathrm{~min}$ at $94^{\circ} \mathrm{C}$. This amplification was followed by incubations of $1 \mathrm{~min}$ at $55^{\circ} \mathrm{C}$ and $3 \mathrm{~min}$ at $72^{\circ} \mathrm{C}$. PCR products were electrophoresed in a $1.3 \%$ agarose gel, stained with ethidium bromide and photographed as above.
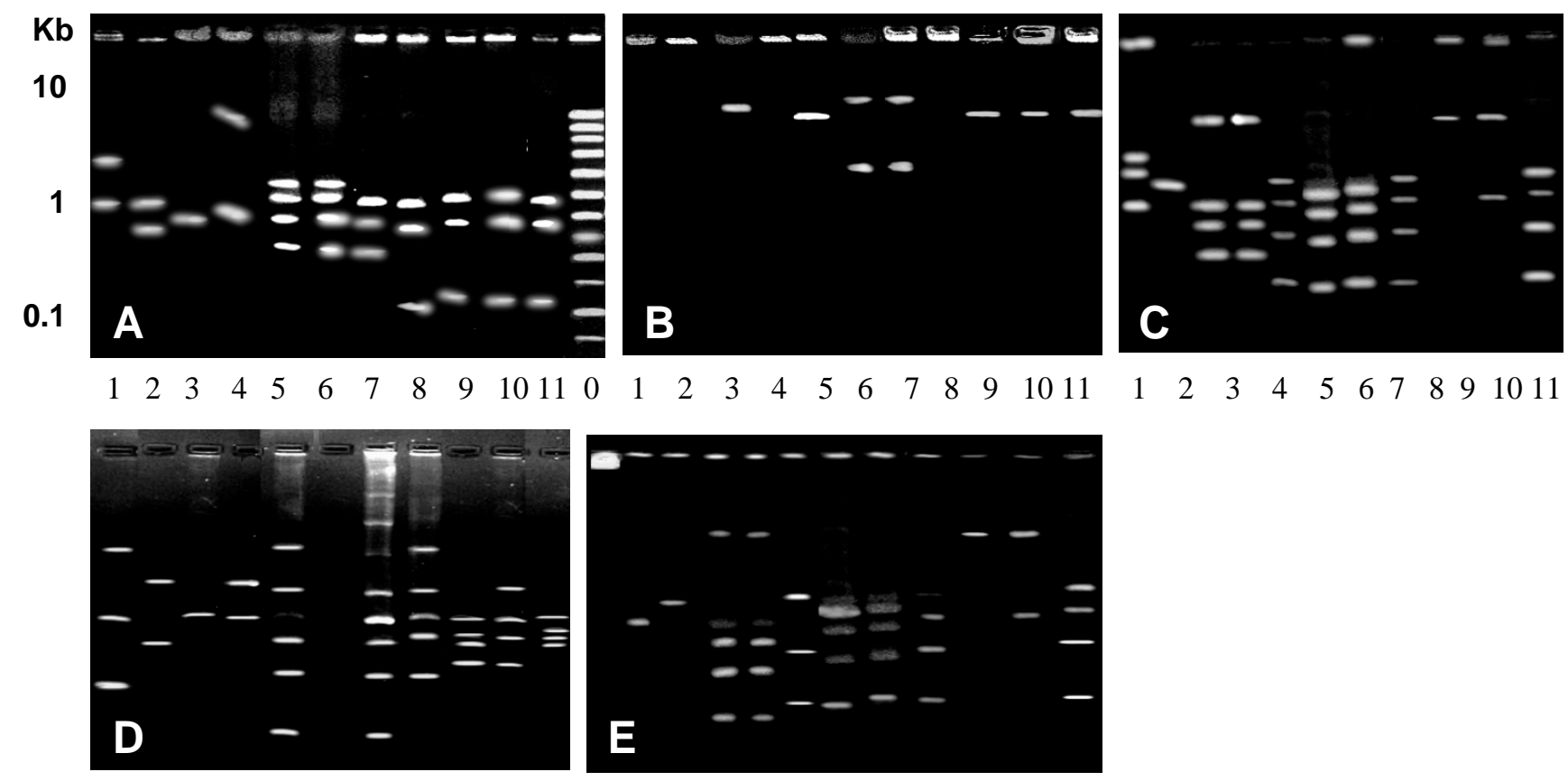

$\begin{array}{lllllllllllllllllllllll}1 & 2 & 3 & 4 & 5 & 6 & 7 & 8 & 9 & 10 & 11 & 1 & 2 & 3 & 4 & 5 & 6 & 7 & 8 & 9 & 10 & 11 & 12\end{array}$

Fig. (1). Restriction endonuclease analysis of kDNA of Trypanosoma isolates. (A) kDNA+EcoR I; (B) kDNA+Bamh I; (C) kDNAs+Hae III; (D) kDNAs+Hinf I; and (E) kDNA+Msp I. Lane 1: T. cruzi (TC) Maracay strain; Lane 2: T. cruzi (TY) strain Y; Lane 3: T. cruzi (TCL) strain CL; Lane 4: isolate TP702; Lane 5: isolate TP704; Lane 6: isolate TP706; Lane 7: isolate TP504; Lane 8: T. rangeli (TRa, CajamarcaPeru strain); Lane 9: isolate TRa605; Lane 10: isolate TRa606 and Lane 11: isolate TM5. Lane 12: Intact kDNA T. cruzi Maracay strain. Size markers are $1 \mathrm{~Kb}$ DNA ladder fragments (Lane 0). 


\section{Statistical Study}

The statistical methods were based on individual hierarchical cluster analysis, selecting the Euclidean distance to the square as the basis for measuring the associations between individuals. The Euclidean distance was calculated by the following grouping procedures of: simple linkage $\left(\mathrm{R}_{\mathrm{k}}\right.$ $0.7355)$, average linkage among groups $\left(R_{k} 0.7518\right)$, average linkage $\left(R_{k} 0.7726\right)$, centroid method $\left(R_{k} 0.7586\right)$, median method $\left(R_{k} 0.7204\right)$, and the Ward method $\left(R_{k} 0.7570\right)$. The cophenetic coefficient $\left(\mathrm{R}_{\mathrm{k}}\right)$ measures the degree of distortion between relationships, means in terms of original distances between individuals and those existing at the end of the analysis. The one with the highest cophenetic correlation was chosen as the optimal method.

In the selection procedures the average linkage between groups was considered, using the coefficient $\mathrm{R}_{\mathrm{k}}$ of Rand, which is an index of the similarity between classifications. This analysis was made with the StatGraphics program, version 5.0.

\section{RESULTS}

The DNA from the kinetoplast of the 7 isolates and the 4 reference strains were purified and then digested with five restriction enzymes (EcoR I, BamH I, Hae III, Hinf I, and Msp I). Electrophoresis using agarose gel revealed that the smaller DNA restriction fragments that resulted after digestion did penetrate the gel, and a complete cleavage of kDNA by the endonucleases was characterized by a total disappearance of DNA from the top of the gel (Fig. 1). Electrophoresis using agarose gel revealed that while intact kDNA was not able to penetrate the gel (Fig. 1E, lane 12). Only BamH I proved incapable of digesting all the kDNA of the TP702, TRa, TRa606, and TM5 isolates (Fig. 1B, lines 1, 2, 4 and 8).

The three reference stocks (TC, TY, and TCL) had very similar restriction cleavage patterns, with the endonucleasas EcoR I and BamH I, but were completely different for the enzymes Hinf I, Hae III and Msp I. The isolates TP702,
TP704, TP706, and TP504 had very similar profiles for almost all of the restriction enzymes (Fig. 1, lines 5, 6, 7 and 8) except for the isolate TP706 with the enzyme Msp I, where the kDNA was not digested to the same degree as isolate TP702 for the enzyme BamH I. The reference stock TRa and the isolated TRa605 and TRa606 had quite similar profiles although completely different from the rest (Fig. 1, lines 2, 3, and 4). The isolate from Mexico, TM5, had a different electrophoretic profile although to a certain extent it can be considered closer to the isolates TRa, TRa605, and TRa606.

When Duplex PCR assay (with T189Fw, Tc189Rv3, TrF3 and TrR8 primers) was used in genomic DNA samples from the different isolates assayed and of the four reference stocks, it was found that the reference stocks of $T$. cruzi (TCL, TY and TC) presented one amplification product, 100-bp (Fig. 2, lines 9, 10, and 11). The isolates from Peru (TP702, TP704, and TP706) had similar DNA fingerprints (Fig. 2 lines 3, 4, and 5). The reference stocks characterized as $T$. rangeli presented as an amplification product a band of 500 bp (Fig. 2 line 8), the Peruvian isolates (TRa605 and TRa606) and the isolate from Mexico (TM5) also presented this same band (Fig. 2 lines 6, 7, and 1, respectively), and the isolate TP504 presented two bands as its amplification product, although one of these had $100 \mathrm{bp}$ and the other approximately 500 bp (Fig. 2, line 2).

\section{DISCUSSION AND CONCLUSION}

Many assays have been made with the aim of investigating the correlation between stocks, using markers based on the variation in the restriction pattern of kinetoplast DNA (kDNA). The pattern of the fragments obtained after digestion with restriction endonucleases and gel electrophoresis is usually complex, but it can be specific for groups, species, or even isolates [15], this being known as schizodeme analysis. Mitochondrial DNA has shown the particularity of containing repetitive elements and regions that vary their homology between different species or complexes. Some of these regions are very conserved, while others are variable and differ

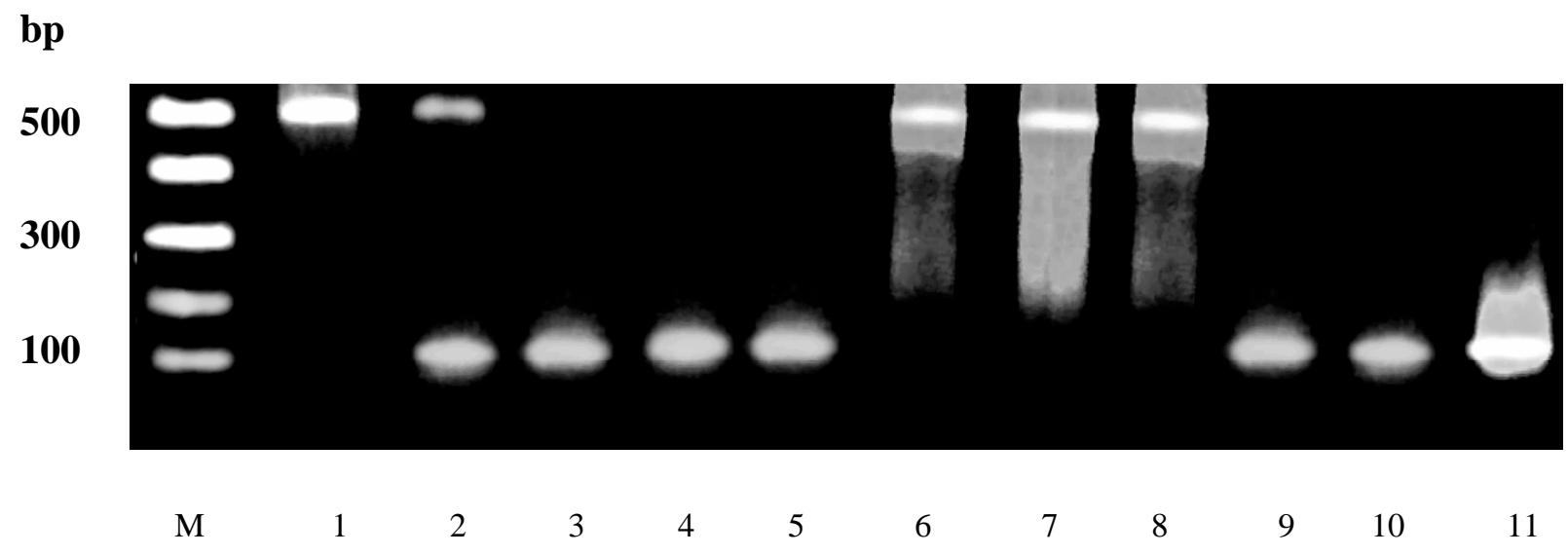

Fig. (2). Amplification products of the PCR multiplex assay from different Trypanosoma strains and isolates, using the primers: T189Fw2, Tc189Rv3, TrF3 and TrR8. In each lane $10 \mu 1$ of sample were placed. Lane 1: isolate TM5; Lane 2: isolate TP504; Lane 3: isolate TP702; Lane 4: isolate TP704; Lane 5: isolate TP706; Lane 6: isolate TRa605; Lane 7: isolate TRa606; Lane 8: T. rangeli (TRa, Cajamarca-Peru strain); Lane 9: T. cruzi (TCL) strain CL; Lane 10: T. cruzi (TY) strain Y and Lane 11: T. cruzi (TC) Maracay strain. Lane M: 100-bp DNA ladder; the lower band shown is 100-bp. Expected products sizes were 100-bp for T. cruzi isolates and 500-bp for T. rangeli isolates. 
between the species or isolates [1]. Mitochondrial genes have evolved more rapidly than have nuclear genes, and therefore the rapid evolution of kDNA can be used in the phylogenetic study of the kinetopastid group [17].

In the present study, we obtained the kDNA from seven stocks and from the four reference stocks. This kDNA having been submitted to the action of 5 restriction endonucleases (EcoR I, BamH I, Hae III, Hinf I, and Msp I). After the statistical analysis of hierarchical cluster grouping by average linkage methods and by using Euclidean distance, made on the basis of the restriction cleavage patterns, the isolates were grouped into 3 clusters. A first cluster containing $T$. cruzi stock Maracay, the stock $T$. cruzi strain Y (TY) and $T$. cruzi strain CL (TCL). The second cluster including the isolate TP702, phylogenetically very close to $T$. cruzi Y and $T$. cruzi CL, the isolates TP704 and TP706, as well as phylogenetically farther from TP702, the isolate TP504, which come quite close to the third cluster formed by $T$. rangeli, the two isolated from Peru (TRa605 and TRa606), and the isolate from Mexico, TM5.

The genomic DNA was used for the specific amplification by the PCR technique. Chiurillo et al. [8] demonstrated that subtelomeric sequences of $T$. cruzi and $T$. rangeli are appropriate for species-specific Duplex PCR detection of these parasites in complex biological samples. The sensitivity reached by duplex PCR is similar to that reported for single $T$. rangeli PCR-typing assays with primers targeted at other nuclear sites $[18,19]$. The duplex PCR assay published by Chiurillo et al. [8] to detect $T$. cruzi and $T$. rangeli with these primers produced a band of $100 \mathrm{bp}$ with $T$. cruzi, while $T$. rangeli gave a band of some $170 \mathrm{bp}$ and minor highmolecular-weight bands. Our results coincide partially with those of these authors; with the duplex PCR assays; we got a 100-bp band for the three stocks of $T$. cruzi used as a reference and which is common for the stocks isolated from Triatoma species of western Peru (TP702, TP704, and TP706). However, in the case of $T$. rangeli (TRa), the band that was amplified was $500 \mathrm{bp}$, slightly greater than the Duplex PCR products obtained by the above-mentioned authors, but consistent with the results of these same authors with individual PCR assay, where they report some minor specific amplification products of the higher molecular weight (500 bp). Also, this discrepancy may be due to the different origin of the isolates, in the present work all coming from tiatomine vectors, whereas the isolates of Chiurillo et al. [8] are of human, dog, Macacus sp. and R. prolixus. The 500-bp band coincides with the two stocks isolated from the salivary glands of Rhodnius ecuadoriensis (TRa605 and TRa606) and with the isolate of T. dimidiate (TM5) in the Yucatan Peninsula de Mexico. The isolate of Panstrongylus chinai (TP504) presented, as the PCR product, two bands, one of $100 \mathrm{bp}$ coinciding with that of $T$. cruzi, and a second band coinciding with the band detected for $T$. rangeli. This suggests that there was a mixture between $T$. cruzi and $T$. rangeli. To test this possibility, we undertook a new cloning, which gave the same result.

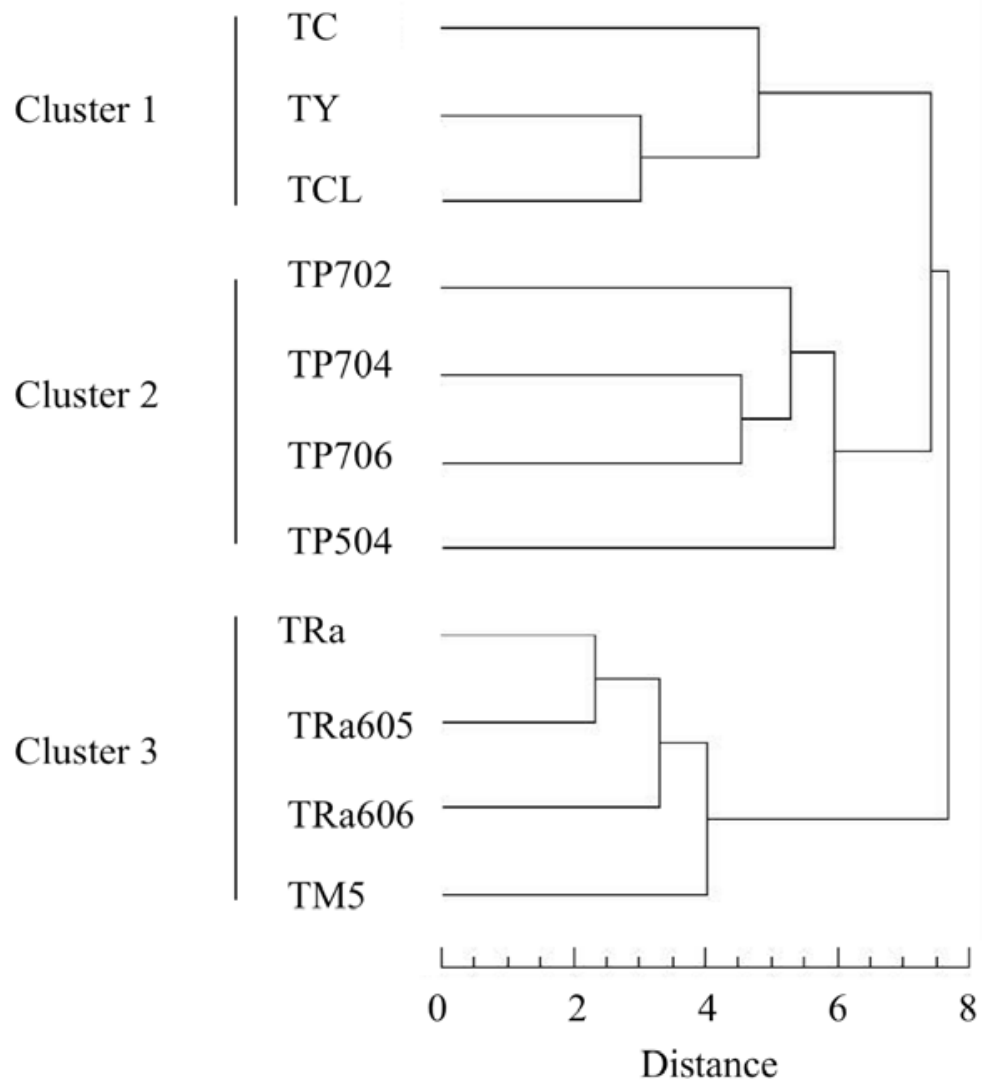

Fig. (3). Dendrogram based on individual hierarchical cluster analysis (Program Stat-Graphics version 5.0). 
In a previous study [5], we characterized these seven stocks and their corresponding reference stocks by lectin agglutination, isoenzyme analysis, and the end products excreted. When these data were statistically treated, together with the data from the present study, we found a grouping of these stocks by hierarchical cluster analysis (or dendogram), as reflected in Fig. (3). According to these data, we have three clusters: cluster 1 contains three T. cruzi stocks, used as references. Very close to the stocks TY and TCL would be the stocks isolated in the Peruvian Amazon (TP702, TP704, and TP706), which would form cluster 2 , and also include stock TP504, although this would be a hybrid between $T$. cruzi and T. rangeli. The separation between the new Peruvian isolates and the $T$. cruzi reference strains may be because the new isolated were obtained in a wild environment, while the reference strains are from a domestic genotype. Cluster 3 would be composed of the trypanosoma isolates from salivary glands (TRa, TRa605, TRa606, and TM5), these four stocks being the same $T$. rangeli stock and the phylogenetic separation observed could be due to having been isolates from different hosts and different geographical regions, as happened with the stocks considered to be $T$. cruzi [20]. These findings completely confirm previous ones for the same stocks [5]. The PCR assay distinguished $T$. cruzi from T. rangeli; this is important because a mixed infection of $T$. cruzi/T. rangeli can occur [2]. Today, PCR is the diagnostic method of choice since it has a high sensitivity and gives a species-specific diagnosis [21]. All these groupings establish a certain correlation between the geographical distribution of the origin of the isolates with the identity of the species.

It is necessary to differentiate and characterize parasite populations in order to establish better diagnosis, treatment, prognosis, control, and the influence that the intraspecific variations can have in epidemiology of these diseases. The techniques used in this study have enabled the quick identification of Trypanosoma spp. Isolates for epidemiological purposes in areas where Chagas disease is endemic, and where $T$. cruzi/T. rangeli parasitism is mixed.

\section{INDEX DESCRIPTORS AND ABBREVIATIONS}

Trypanosoma cruzi strains; characterization; kDNA; restriction enzymes; multiplex PCR assay; Peru; Mexico; Hae III; BamH I; Hinf I; Msp I; EcoR I; TC, T. cruzi strain Maracay; TY, $T$. cruzi strain Y; TCL, T. cruzi strain CL; TRa, $T$. rangeli; TM5, trypanosome isolate from Triatoma dimidiate in the Yucatan Peninsula of Mexico; TP504, trypanosome isolate of Panstrongylus chinai in Peru; TP702, trypanosome isolate from Triatoma carrioni in Peru; TP706, trypanosome isolate from T. herreri in Peru; TP704, trypanosome isolate of $T$. infestans in Peru; TRa605 and TRa606, trypanosomes isolates from the salivary glands of two Rhodnius ecuadoriensis in Peru.

\section{ACKNOWLEDGEMENTS}

This investigation received financial supports from MEC (Spain) - CGL2006-27889-E/BOS.

\section{REFERENCES}

[1] Rodríguez P, Montilla M, Nicholls S, Zarante I, Puerta C. Isoenzymatic characterization of Colombian strains of Trypanosoma cruzi. Mem Inst Oswaldo Cruz 1998; 93: 739-740.

[2] Machado CA, Ayala FJ. Nucleotide sequences provide evidence of genetic exchange among distantly relasted lineages of Trypanosoma cruzi. Proc Natl Aca Sci USA 2001; 98: 7396-7401.

[3] Guzmán-Marín ES, Zava1a-Castro JE, Acosta-Viana KY, RosadoBarrera ME. The Importance of the caracterization of Trypanosoma cruzi strains. Rev Bromed 1999; 10(3):234-245.

[4] Organización Panamericana de la Salud/ Organización Mundial de la Salud Agencia Canadiense para el Desarrollo Internacional. Proyecto de Eliminación de Triatoma infestans. Visita de Monitoreo. Lima, Arequipa, Moquegua 11-15 julio 2004.

[5] Rodríguez-Gonzalez I, Marín C, Hitos AB, Rosales MJ, GutierrezSánchez R, Sánchez-Moreno M. Biochemical characterization of new strains of Trypanosoma cruzi and Trypanosoma rangeli isolates from Peru and Mexico. Parasitol Res 2004; 94: 294-300.

[6] Steindel M, Toma HK, Ishida M, Murta SM, de Carvalho-Pinto CJ, Grisard EC, Schlemper BR, Ribeiro-Rodrigues R, Romanha AJ. Biological and isoenzymatic characterization of Trypanosoma cruzi strains isolated from sylvatic reservoirs and vectors from the state of Santa Catarina, Southern Brazil. Acta Trop 1995; 60:167-177.

[7] Miralles DM, Marín C, Magán R, Fernández-Ramos C, Entrala E, Cordova O, Vargas F, Sánchez-Moreno M. In vitro culture and biochemical characterization of six trypanosome isolates from Peru and Brazil. Exp Parasitol 2002; 102: 23-29.

[8] Chiurillo MA, Crisante G, Rojas A, Peralta A, Dias M, Guevara P, Añez N, Ramírez JL. Detection of Trypanosoma cruzi and Trypanosoma rangeli infection by duplex PCR assay based on telomeric sequences. Clin Diag Labor Inmunol 2003; 10(5): 775-779.

[9] Silva LHP, Nussenzweig V. Sobre una cepa de Trypanosoma cruzi altamente virulenta para o camundongo branco. Folia Clin Biol 1953; 20: 191-203.

[10] Brener Z, Chiari E. Variaçoes morfológias observadas amostras de Trypanosoma cruz. Rev Inst Med Trop Sao Paul 1963; 5: 220-224.

[11] Sánchez-Moreno M, Férnandez-Becerra C, Castilla J, Osuna A. Metabolism studies by ${ }^{1} \mathrm{H}$ NMR of different forms of Trypanosoma cruzi strains as obtained in vitro culture. FEMS Microbiol Lett 1995; 133: 119-125.

[12] Gonçalves AM, Nehme NS, Morel CM. Trypanosomatid characterization by schizodeme analysis. In: Genes and Antigens of Parasites (A Laboratory Manual) (Morel, C.M., Ed.) $2^{\text {nd }}$ edn. Fundaçao Oswaldo Cruz, Rio de Janeiro, RJ, Brazil 1984.

[13] Riou G, Yot P. Heterogeneity of the kinetoplast DNA molecules of Trypanosoma cruzi. Biochem 1977; 16: 2390-2396.

[14] Chiurillo M, Peralta A, Ramírez JL. Comparative study of Trypanosoma rangeli and Trypanosoma cruzi telomeres. Mol Biochem Parasitol 2002; 100: 173-183.

[15] García HA, Mendoza-León A. Molecular diagnostic in Kinetoplastida Protozoa. Principles and applications. Rev Fac Cs Vets UCV 2000; 4(4): 109-130.

[16] Hide G, Tait A. The molecular epidemiology of parasites. Experiencia 1991; 7: 128-142.

[17] McManus I, Bowles J. Molecular genetic approaches to parasite identification: their value in diagnostic parasitology and systematics. Int J Parasitol 1996; 26(7): 687-704.

[18] Souto RP, Vargas N, Zingales B. Trypanosoma rangeli: discrimination from Trypanosoma cruzi based on a variable domain from the large subunit ribosomal RNA gene. Exp Parasitol 1999; 91: 306-314.

[19] Vargas N, Souto RP, Caranza J, Vallejo GA, Zingales B. Amplification of a specific repetitive DNA sequence for Trypanosoma rangeli identification and its potencial application in epidemiological investigations. Exp Parasitol 2000; 96: 147-159.

[20] Grisard EG, Steindel M, Guarneri AA, Eger-Mangrich I, Campbell DA, Romanha AJ. Characterization of Trypanosoma rangeli strains isolates in Central and South America. Mem Inst Oswaldo Cruz 1999; 94: 203-209.

[21] Schwartz E, Hatz C, Blue J. New World cutaneous leihmaniasis in travellers. Lancet Infect Dis 2006; 47: 349-358. 